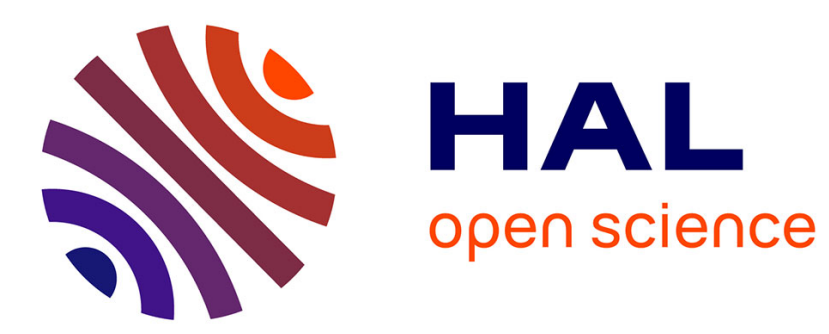

\title{
Overview of Electromagnetic Transducers with Radar Interrogation for Passive Wireless Sensors Applications
}

Patrick Pons, Hervé Aubert, Manos Tentzeris

\section{To cite this version:}

Patrick Pons, Hervé Aubert, Manos Tentzeris. Overview of Electromagnetic Transducers with Radar Interrogation for Passive Wireless Sensors Applications. International Conference on Microwaves, Radar and Wireless Communications (MIKON), Jun 2014, Gdansk, Poland. hal-01024205

\section{HAL Id: hal-01024205 \\ https://hal.science/hal-01024205}

Submitted on 29 Jul 2014

HAL is a multi-disciplinary open access archive for the deposit and dissemination of scientific research documents, whether they are published or not. The documents may come from teaching and research institutions in France or abroad, or from public or private research centers.
L'archive ouverte pluridisciplinaire HAL, est destinée au dépôt et à la diffusion de documents scientifiques de niveau recherche, publiés ou non, émanant des établissements d'enseignement et de recherche français ou étrangers, des laboratoires publics ou privés. 


\section{Overview of Electromagnetic Transducers with Radar Interrogation for Passive Wireless Sensors Applications}

\author{
Patrick PONS, Hervé AUBERT \\ CNRS, LAAS, 7 avenue Roche, F-31400 Toulouse, France \\ Toulouse University, LAAS, F-31400 Toulouse, France
}

\author{
Manos TENTZERIS \\ School of ECE, Georgia Inst. of Tech., Atlanta, U.S.A
}

\begin{abstract}
Passive wireless sensors with electromagnetic transduction are chipless wireless sensors that do not require electronic circuits or power. They are then good candidate for buried sensors or harsh environment applications. We validated at LAAS several transducers concepts with high sensitivity (pressure, stress, temperature, radiation) compatible with radar interrogation up to several ten of meters.
\end{abstract}

Index Terms-wireless sensor, passive sensor, chipless sensor, electromagnetic transduction, radar interrogation

\section{INTRODUCTION}

All the European prospective (ARTEMIS, EPoSS, ENIAC, H2020) show that "Intelligent Cyber-physical Systems" will play a key role in many sectors (Energy, Transport, Security, Telecommunications, Health Care, Environment, ....) in the next decade. Also called "Internet of Object" or "Ambient Intelligence", this issue puts the smartness in the heart of the "Objects" that will be able to interact with their environment and to communicate to bring new features and new services. In this context Wireless Sensors Networks (WSN) appear as a key technology for a lot of applications.

Wireless sensor consists of two separate units (the sensing unit and the reader) that communicate most of the time using RF waves. Like wired sensors, wireless sensors requirements concern their accuracy, selectivity, response time, reliability, ... and also their size and cost. The specificity of the wireless link leads to additional constraints such as energy autonomy, interrogation distance, identification and data rate. All these specifications may be very different because they are applications dependent and lead to different trade off (technology, design, frequency, ...).

In the early 2000s, the availability of miniature MEMS sensors, low power communication modules, highperformance miniature batteries and standard communications protocols ( Zigbee , Bluetooth, ... ) opened the way for the development of "active" wireless sensors and this kind of products are currently available on the market. The "active" terminology refers here to the use of a RF transmitter (inside the sensing unit) to communicate with the reader. The main drawback of this kind of sensors concerns the energy autonomy that is limited on one hand by the amount of energy stored in the battery and on other hand by the sensing unit consumption. Significant research efforts have been then undertaken in the world, since the early 2000 s, on energy harvesting (solar, mechanical, thermal, RF, ....), on high capacity storage units, on new nuclear energy efficient microsource (electrochemical , thermoelectric , thermionic , ... ) but also on circuits with very low power consumption. However this kind of solutions is not adequate for all the application; that is why "passive" wireless sensors was studied in parallel.

For "passive" sensors, the RF transmitter is removed from the sensing unit and communication with reader is based on backscattering solutions that allows to remove the battery. Two kinds of solutions are developed for long range interrogation $(\gg>1 \mathrm{~m})$. The first one use more or less complex electronics components integrated in the sensing unit (digital modulation of radar cross section [1] or intermodulation techniques [2]). The second one is called "chipless" as all electronics components have been removed. The oldest example is given by SAW (Surface Acoustic Wave) sensor for which the operating principle is based on the generation of an acoustic wave on the surface of a piezoelectric material through an antenna [3]. However all these solutions provide interrogation distance typically lower than $10 \mathrm{~m}$ that can be too low for several applications.

In order to overcome this restriction, new kind of electromagnetic transducers are developed since the mid2000s. The operating principle is based on the modification of the properties of high-frequency $(\gg>1 \mathrm{GHz}$ ) passive electromagnetic device by the quantity to be measured. A wide range of sensing properties can be addressed with this principle with the use of a great choice of materials. Another advantage is the use of high frequency that allows to reduce the size elements (antenna, transducer), to increase the antenna directivity, to enhanced immunity to multipath and to increase the available bandwidth. In this paper we present an overview on these studies done at LAAS since 2005. 
TABLE I. LIST OF FIRST PUBLICATIONS ON DIFFERENT PASSIVE SENSORS WITH ELECTROMAGNETIC TRANSDUCTION

\begin{tabular}{|c|c|c|c|c|}
\hline Year & Ref & Laboratory & $\begin{array}{l}\text { Kind of } \\
\text { sensor }\end{array}$ & Transducer principle \\
\hline 2004 & {$[12]$} & $\begin{array}{c}\text { California Univ. } \\
\text { USA }\end{array}$ & Gas & $\begin{array}{c}\text { Variation of resonator } \\
\text { permittivity }\end{array}$ \\
\hline 2005 & [13] & $\begin{array}{l}\text { Manitoba Univ } \\
\text { Canada }\end{array}$ & Stress & $\begin{array}{c}\text { Variation of air cavity } \\
\text { length }\end{array}$ \\
\hline 2007 & [14] & $\begin{array}{c}\text { LAAS/CNRS } \\
\text { France }\end{array}$ & Pressure & $\begin{array}{c}\text { Variation of coupling } \\
\text { between planar } \\
\text { resonator and } \mathrm{Si} \\
\text { membrane }\end{array}$ \\
\hline 2007 & {$[15]$} & $\begin{array}{l}\text { Perdue Univ. } \\
\text { USA }\end{array}$ & Temperature & $\begin{array}{c}\text { Variation of coupling } \\
\text { between air cavity and } \\
\text { cantilevers }\end{array}$ \\
\hline 2008 & {$[16]$} & $\begin{array}{c}\text { Georgia Tech } \\
\text { USA }\end{array}$ & Flux & $\begin{array}{c}\text { Variation of coupling } \\
\text { between air cavity and } \\
\text { membrane }\end{array}$ \\
\hline 2009 & {$[17]$} & $\begin{array}{l}\text { Tokyo Inst. } \\
\text { Tech. } \\
\text { Japan }\end{array}$ & Crack & $\begin{array}{c}\text { Variation of effective } \\
\text { length of dipole } \\
\text { antenna }\end{array}$ \\
\hline
\end{tabular}

\section{TRANSDUCERS}

Electromagnetic transducers are mainly composed of a variable $\mathrm{RF}$ impedance or RF resonator connected to an antenna that can be interrogated through backscattered wave analysis. Several concepts are possible to realize a sensor with this kind of device by changing the size, the RF properties of a material constituting the device, the coupling between different parts of the device (using displacement of fluid or mechanical part). At LAAS we investigated the last solution that provides very high sensitivity and we developed transducers working generally at frequency of few ten of $\mathrm{GHz}$.

Membrane displacement has been used at LAAS for pressure [4-5] temperature [6-7], stress [8-9] and radiation [10] transducers.

For pressure transducer a high resistivity silicon membrane is fabricated above a planar half-wavelength resonator deposited inside a few microns depth glass cavity. The membrane deflection leads to a modification of coupling between the silicon and the resonator evanescent wave that modifies the resonant frequency of the device. For resonator-membrane air gap lower than $10 \mu \mathrm{m}$, the frequency shift is linear and can achieve sensitivity up to $5 \% / \mu \mathrm{m}$ depending on the membrane thickness.

The temperature transducer is based on split ring resonators in which each ring is closed by a variable capacitor formed by the metal ring and a bimorph micro-cantilever. The temperature shift will induce a cantilever deflection and then a capacitance modification that changes the resonant frequency of the device. For cantilever-ring distance lower than $10 \mu \mathrm{m}$ frequency shift up to $8 \% / \mu \mathrm{m}$ can be obtained.

The stress transducer is based on a patch antenna loaded with an open loop in two orthogonal sides in order to sense the stress independently in the two plane directions. Each loop is closed by a variable capacitor formed by the fixed part of the loop and the free end of a metallic cantilever. A substrate deformation causes a displacement of the anchoring point of the beam leading to a modification of the capacitor area and then changes the resonant frequency of the device. Sensitivity around $4.5 \mathrm{ppm} / \mu \varepsilon$ can be obtained that are 4 times greater than existing strain transducers of the same class.

The radiation transducer principle is based on polymer (High Density PolyEthylene) outgasing inside a micro-chamber etched in silicon wafer. The generated over-pressure leads to a silicon membrane deflection that modifies the resonant frequency of the RF resonator (see section on pressure transducer). The objective is to develop a wireless sensor for very high doses (10kGy - $10 \mathrm{MGy})$. Tests structured have been designed and fabricated to validate the technology and the HDPE outgazing. Membrane deflections around $0.1 \mu \mathrm{m} / \mathrm{kGy}$ have been obtained for doses up to $40 \mathrm{kGy}$. This membrane deflection will induce relative resonance frequency shift around $0.8 \% / \mu \mathrm{m}(8 \% / 100 \mathrm{kGy})$ for $10 \mu \mathrm{m}$ initial air gap and $400 \mu \mathrm{m}$ thick silicon membrane.

Temperature transducer principle using thermal dilatation of metallic [11] and dielectric [12-13] fluids in micro-channel have been validated at LAAS.

The first one is based on $\lambda / 2$ dipole antenna array with progressive short circuiting of the two dipole strands by the metallic liquid when the temperature increase, leading to a drastically change of the antenna array Radar Cross Section (RCS) for each short-circuit. RCS variation around $12 \mathrm{sBsm}$ has been obtained for the full scale.

The second one is based on coplanar gap capacitor whose value is modified by the progressively filling of gap capacitor with a dielectric fluid, leading to a modification of the scattering parameter S11. S11 shift around $8 \mathrm{~dB}$ between empty and full channel has been obtained.

\section{WIRELESS INTERROGATION}

FMCW (Frequency Modulated Continuous Wave) Radar has been chosen at LAAS for the wireless interrogation of the electromagnetic transducers. This kind of Radar is simpler than UWB (Ultra Wide Band) Radar and is more compatible with high interrogation distance.

FMCW radar is used to measure the RCS variation of the target that is done generally by the transducer connected to an antenna. The signal back-scattered by the target is mixed with the transmitted signal to obtained the beat frequency spectrum. By adding a delay line between the transducer and the antenna it is possible to separate the antenna echo from the transducer echo whose level varies with quantity to measure [5 \& 14]. This technique has been successfully applied to the wireless interrogation of the different transducers described previously and has been validated for interrogation distance up to $20 \mathrm{~m}$ with $20 \mathrm{~mW}$ input signal and $14 \mathrm{dBi}$ antennas. These results have been obtained without complicated signal treatment showing that interrogation distance of several ten of meters may be achievable with efficient noise filtering. The main drawbacks of this technique based on echo level are the low accuracy (around $10 \%$ of the full scale) and the sensitivity to 
parasitic signal attenuation that involves the use of reference sensor. But these drawbacks can be overcome with FCMW radar able to track the frequency for which the RCS is maximum.

Specific delay lines are also used to create low frequency bar code for sensors identification [14-15]. In this case, the beat frequency difference between the antenna echo and the transducer echo will provide the identification. We evaluated to 30 the number of different sensors that can be identified in a given direction by the same radar.

\section{ACKNOWLEDGMENT}

Pressure transducer and radar development has been partly supported by the French Project of 'Pôle de compétivité' entitled 'Système Autonome Communicant En Réseau' (SACER).

Studies on temperature and stress transducers have been performed in collaboration with Georgia Institute of Technology (USA)

Radiation sensor study is done in the framework of FP7-MNTERA.NET-DOSIMEMS, funded by Midi-Pyrénées Region and done in collaboration with National Centre for Nuclear Research (Otwock, Poland, M. Olszacki) and Wroclaw University of Technology (Wrocław, Poland, J. Dziuban, P. Knapkiewicz).

All these studies have been performed with the assistance of M. Jatlaoui, F. Chebila, T. Thai, S. Bouaziz, A. Traille, A. Rifai, E. Debourg, I. Augustyniak.

\section{REFERENCES}

[1] T Sanchez Lopez. RFID and sensor integration standards: State and future prospects. Computer Standards \& Interfaces 33 (2011) 207-213

[2] V. Viikari, J. Song, H. Seppa, Passive wireless sensor platform utilizing a mechanical resonator, IEEE Sensors journal, Vol.13, N 4 , april 2013

[3] A Pohl, A Review of Wireless SAW Sensors. IEEE Transactions on Ultrasonics, Ferroelectrics, and Frequency Control, vol. 47, no. 2, march 2000

[4] M Jatlaoui, P. Pons, H.Aubert, Radio Frequency Pressure Transducer . European Microwave Week (EUMC2007), 8-12 October 2007, Munich, Germany
[5] M. Jatlaoui, F. Chebila, P. Pons, H. Aubert, Working Principle Description of the Wireless Passive EM Transduction Pressure Sensor. European Physical Journal - Applied Physics, Vol 56, N 1 , oct 2011

[6] T. Thai, M Jatlaoui, H Aubert, P Pons, G. DeJean, M Tentzeris, R Plana , A Novel Passive Wireless Ultrasensitive Temperature RF Transducer for Remote Sensing, International Microwave Symposium, May 23-28 2010, Anaheim (USA)

[7] T. Thai, M. Jatlaoui, F. Chebila, H. Aubert, P. Pons, G. DeJean, M. Tentzeris, R. Plana, Design and Development of a Novel Passive Wireless Ultrasensitive RF Temperature Transducer for Remote Sensing. IEEE Sensor Journal Volume12, Issue 8, sept 2012, pp 27562766

[8] T. Thai, H. Aubert, M. Tentzeris, P. Pons, R. Plana, Design of a Highly Sensitive Wireless Passive RF Strain Transducer, International Microwave Symposium, June 5-10 2011, Baltimore (USA)

[9] T. Thai, H. Aubert, P. Pons, G. DeJean, M.Tentzeris, R. Plana, Novel Design of a Highly Sensitive RF Strain Transducer for Passive and Remote Sensing in Two Dimensions, IEEE Transactions on Microwave Theory and Techniques, Issue 3, March 2013, pp 1385-1396

[10] I. Augustyniak, P. Knapkiewicz, J. Dziuban, M. Matusiak, M. Olszacki, P. Pons, MEMS high-doses radiation sensor, Conference on Solid State Sensors, Actuators and Microsystems, June 16-20 2013, Barcelona, Spain

[11] A.Traille, S.Bouaziz, H.Aubert, P.Pons, M.Tentzeris, A Novel Wireless Passive Temperature Sensor Utilizing Microfluidic Principles in Millimeter-Wave Frequencies IEEE Sensors, 28-31 October 2011,Limerick, Ireland

[12] S. Bouaziz, F. Chebila, A. Traille, P. Pons, H. Aubert, M. Tentzeris, A New millimeter-wave micro-fluidic Temperature sensor for wireless passive radar interrogation, IEEE sensors 2012, October 28-31 2012, Taipei, Taiwan

[13] S. Bouaziz, F. Chebila, A. Traille, P. Pons, H. Aubert, M. Tentzeris, Novel Micro-fluidic Structures for Wireless Passive Temperature Telemetry Medical Systems Using Radar Interrogation Techniques in Ka-band, IEEE Antennas \& Wireless Propagation Letters, Volume 11, Janv 2013, pp 1706-1709

[14] H. Aubert, H. Aubert, F. Chebila, M. Jatlaoui, T. Thai, H. Hallil, A. Traille, S. Bouaziz, A. Rifaï, P. Pons, P. Menini, M. Tentzeris, Wireless Sensing and Identification based on RADAR Cross Sections Variability Measurement of Passive Electromagnetic Sensors, Annals of telecommunications, vol. 68, no7-8, June 2013, pp. 425-435

[15] M. Jatlaoui, F. Chebila, S. Bouaziz, P. Pons, H. Aubert. Original Identification technique of passive EM Sensors using Loaded Transmission Delay Lines. European Microwave Week (EUMC2010), 26 Sept-1 Oct 2010, Paris, France 